\title{
Gallensteine - Quiz zur Zertifizierung
}

\author{
Nur eine Antwortmöglichkeit ist jeweils richtig!
}

1. Welche der folgenden Situationen ist ein typischer Risikofalktor für die Entstehung von Gallenblasensteinen?

A: Rapide Gewichtszunahme

B: Langfristige enterale Ernährung

C: Schwangerschaft

D: Distal betonte Colitis ulcerosa

E: Refluxkrankheit der Speiseröhre

2. Welcher diagnostische Schritt ist Methode der Wahl bei klinischem Verdacht auf das Vorliegen einer Cholezystolithiasis?

A: Computertomographie

B: Abdominelle Sonographie

C: Intravenöse Cholangiographie

D: Röntgenzielaufnahme nativ

E: Biliäre Szintigraphie

3. Welches ist keine typische Komplikation der Cholezystolithiasis?

A: Akute Cholezystitis

B: Zystikusverschluss mit Gallenblasenhydrops

C: Bouveret-Syndrom

D: Gastroduodenales Ulcus

E: Steinabgang mit biliärer Pankreatitis

4. Häufige Komplikationen der endoskopischen Sphinkterotomie des Gallenganges sind

A: Blutung, retroduodenale Perforation, akute Pankreatitis

B: Diarrhoe, akute Pankreatitis, retroduodenale Perforation

C: Blutung, enteroduodenale Fistel, akute Pankreatitis

D: Retroduodenale Perforation, Gallenkolik, akute Pankreatitis

E: Blutung, retroduodenale Perforation, chronische Pankreatitis

5. "Therapeutisches Splitting" bedeutet in der Therapie der Choledocho- und Cholezystolithiasis

A: laparoskopische Cholzystektomie und nachfolgend offene Gallengangsrevision

B: extrakorporale Stoßwellenlthotripsie von Gallenblasensteinen und nachfolgend chirurgische Entfernung von Gallengangssteinen

C: Cholezystostomie und nachfolgend perkutan-cholangioskopische Entfernung von Gallengangssteinen

D: Endoskopische Entfernung von Gallengangssteinen und nachfolgend Cholezystektomie (vorzugsweise laparoskopisch)

E: Laserlithotripsie von Gallengangssteinen und nachfolgend medikamentöse Lyse von Gallenblasensteinen
6. Welches Kriterium ist unerheblich für die konservative Behandlung der Cholezystolithiasis (extrakorporale Stoßwellenlithotripsie, Lysetherapie)?

A: Gallenblasenfunktion

B: Kalkgehalt der Steine

C: Steinzahl

D: Steingröße

E: Vorhergehende Kolonsegmentresektion

7. Welche( $r$ ) der folgenden Laborparameter ist (sind) am sensitivsten bei der Diagnostik der Choledocholithiasis?

A: Quotient direktes /indirektes Bilirubin

B: C-reaktives Protein (CRP)

C: $\gamma$-GT und alkalische Phosphatase

D: LDL-Cholesterin

E: Laktatdehydrogenase (LDH)

8. Keine typische Komplikation bei der laparoskopischen Cholezystelktomie ist/sind

A: Gallengangsverletzung

B: Blutung

C: Wundinfektion

D: Mirizzi-Syndrom

E: Postoperative Gallengangsstenosen

9. Keine Indikation zur Ilaparoskopischen Cholezystektomie besteht bei

A: asymptomatischem Steinrezidiv nach primär erfolgreicher extrakorporaler Stoßwellenlithotripsie

B: akuter Cholezystitis

C: einem Gallenblasenpolypen über $2 \mathrm{~cm}$ Durchmesser

D: rezidivierenden biliären Koliken bei Cholezystolithiasis

10. Welches Verfahren zur Behandlung von Gallengangssteinen erfordert obligat die direkte optische Kontrolle mittels Cholangioskop?

A: mechanische Lithotripsie

B: elektrohydraulische Lithotripsie

C: Laserlithotripsie mit Stein-Gewebe-Erkennungssystem

D: Extrakorporale Stoßwellenlithotripsie (ESWL)

E: Steinextraktion mit Ballonkatheter

11. Wie viele der Patienten mit Cholezystolithiasis sind bei Diagnosestellung asymptomatisch?

A: Etwa $20 \%$

B: Etwa 35\%

C: Etwa 50\%

D: Etwa $75 \%$

E: Etwa 95\%

(c) Georg Thieme Verlag Stuttgart · New York 